\section{Senior registrar in psychotherapy}

\section{Dear Sirs}

As one of Dr Ryle's SR level trainees in psychotherapy I was pleased to see his views in print (Psychiatric Bulletin, January 1992, 16, 30-32). I found myself agreeing with much of what he had to say but I should like to add something of my personal experience in my peer group as a trainee.

Dr Ryle stresses the importance of an involvement in research yet with notable exceptions only a few of my SR colleagues seem to be actively involved in much research. Few attend the Society for Psychotherapy Research conference each year and possibly even fewer went to the first IPA conference on research in London last year. When I discuss research with them there often seems to be a combination of disinterest in and disinformation about the nature, and practical use of many of the tools valuable in psychotherapy research; tools like numeric methods, audiotaping or questionnaires. The disinterest and disinformation serve to reinforce a distrust of these methods which is not based on a balanced appraisal of either their benefits or their disadvantages. Many give lip service to research but, in connection with my interest in research, I have been asked on more than one occasion why it is that I am training to become a psychotherapist rather than a general psychiatrist which it is implied would be more suitable.

The attitude of the SR body to cognitive and behavioural approaches is also problematic. Such methods are often acknowledged as potentially beneficial in "removing symptoms", especially if a psychodynamic approach has been ruled out for some reason. It is also accepted that SRs need to learn how to identify suitable cases. However, there is little interest in learning how to do these treatments, this component of training where it exists being regarded as, at best, a worthy chore. Actually being keen on doing such treatments may be treated as an indication of being unfeeling, out of touch with the unconscious or no more skilled than any psychiatrist who talks to patients.

This leads me to a personal worry. I have an impression that debate has polarised into one conducted between only psychodynamic and cognitive behavioural therapists. Often some kind of divisional system is proposed with consultants chosen to represent either pure cognitive or pure psychodynamic approaches. While I am reassured that currently the view is that the specialist section should not be split, I find myself worrying that ancient hostilities and different approaches to training will, when combined with an exclusive focus on only two pure lines of treatment, avert de jure separation but perpetuate it de facto.

My experience of my peer group provides me with worrying evidence for this. A principal component of my training so far has been in an approach which combines cognitive and analytic perspectives in a single method of working. Yet often talking with my peers about this it is difficult to get the integrative focus across. I find myself talking to a person who, knowing my interest in cognitive approaches, assumes I must therefore be disinterested in and ignorant of psychodynamic ones.

Purists are vital. They promote excellence but a danger is that they may become rigid and be contemptuous of or patronising towards integrated approaches. I would be sad if the outcome of debate in the College was a victory for purists of whatever sort and this is because one of my chief training experiences has been in the values of integration.

\section{Guy's Hospital}

Chess Denman

\section{London SEI}

\section{Dear Sirs}

Having received a three-and-a-half year psychotherapy training outside London, I was interested to read Anthony Ryle's criticisms. I agree that for a senior registrar to undertake an analytic training on top of a full-time NHS post is likely to preclude social or family life and that the concentration on psychoanalytic thought to the exclusion of real life is likely to be detrimental rather than helpful to prowess as a psychotherapist. I was shocked to meet such a senior registrar last year and discover the sacrifice of time, energy and money that her training involved. If there is little chance of achieving a consultant post in London without an analytic training, this must surely be mistaken. Of course, senior registrars should be free to choose the type of psychotherapy training they wish but we need consultants with a variety of outlooks. To date, the Royal College guidelines have not catered for those who prefer to specialise in behavioural and cognitive therapies, although this is under consideration.

Dr Ryle criticises the overemphasis on seeing longterm patients during training. As there will always be patients who need several years therapy, long-term work should form part of training. But experience of other modes of psychotherapy is vital given that, as consultants, we may be more involved in recommending patients to appropriate modes of therapy than treating them. Most of us are gifted at particular forms of psychotherapy and should develop our skills by concentrating on these while knowing enough about other approaches to be able to point our patients in the right direction, and to value colleagues who work in a different manner. Psychoanalytic institutes, and some psychotherapy training, encourage adherence to one particular set of beliefs at the expense of other training as though ignoring the famous Luborsky finding that all therapies were equal. 
Holmes \& Lindley have argued the need within the NHS to adapt psychoanalytic techniques and values in order to reach the people most in need of psychotherapy. Training at senior registrar level should encourage initiative in tackling this issue.

Finally, the duties of a consultant psychotherapist are more likely to be approached flexibly and humanely by someone with life experience and interest in things outside the psychotherapeutic sphere than by the highly trained practitioner who has not had time to read, listen to music, dig the garden or chat with friends.

Graylingwell Hospital

SOPHIA HARTLAND Chichester PO194PQ

\section{What would you have done?}

DeAr Sirs

The letter from Drs Joyce \& Palia (Psychiatric Bulletin, 1992, 16, 52) reminded me that some years ago an elderly patient continuously and agonisingly screeched, causing great distress in a 25-bedded ward. Her teeth were very carious and the gums infected. She was too demented to give real consent to treatment and her husband, likening dentists and surgeons to butchers, was opposed to treatment. I consulted a member of my medical defence society and he said that if a senior psychiatric consultant colleague, the dentist and I all signed to the effect that we considered dental treatment essential we could go ahead with it. We did so and the result was pleasing to all concerned, including the husband, who bore no resentment.

Joyce \& Palia's patient, not knowing her age or the year, month, season, day or the name or the nature of the place she was in and not remembering having been told she had a stone in her bladder, seems incapable of giving consent to essential treatment and, although questions of consent have become more complicated in recent years, perhaps Joyce and Palia would consider following the same procedure as I did, presumably substituting the appropriate health authority solicitor for the medical defence society.

Fulford Grange Hospital

GeOfFrey Wallis

Micklefield Lane Rawdon

Leeds LS196BA

\section{The standard Eire and other deviations}

Dear Sirs

Professor Fahy (Psychiatric Bulletin, February 1992, $16,113)$ is, of course, quite right: the English name of our homeland is Ireland. However, an ethnic error, if deliberate, can sometimes help to prevent a postal one. Just as mail addressed to Basel, Switzerland, from the United States is not infrequently routed via Brazil or Sweden, whence it may arrive after some delay, mail for Ireland, even if posted in Boston, can take longer to arrive than expected. The "Defensive Strategy", discouraged by Professor Fahy, of insisting that Ireland is a Republic does not always help, for Iceland is a republic as well. But if at least the purveyors of junk mail originating in America were encouraged to locate Dublin (and even Galway) in Eire, their products would be unlikely to be forwarded at all from Zaire.

Psychiatric University Policlinic

C. R. B. JOYCE 3010 Bern.

Switzerland

\section{Resettlement of long-stay patients in the community}

DeAR SirS

We would like to comment on Double \& Wong's (Psychiatric Bulletin, 1991, 15, 735-736) follow-up study of patients resident in Middlewood Hospital on 12 January, 1982.

In general, their findings must give grounds for cautious optimism regarding the resettlement of long-stay patients in the community in Sheffield, although we doubt that there is reason for complacency. HRH Prince of Wales (1991) has succinctly outlined the large gaps that still exist in our knowledge regarding the impact of deinstitutionalisation.

The authors assert that they found no homelessness in their follow-up study of discharged long-stay patients: yet two patients were found to be resident in the Sheffield hostel for homeless men. It is possible that by using such a narrow definition of homelessness (i.e. rooflessness) the authors have underestimated the extent of the problem.

The authors state that studies on community care should distinguish between the needs of acute patients and those of the long stay. This is clearly true. A recent study (Meltzer et al, 1991) drew attention to the impoverished social circumstances of acute psychiatric patients discharged to the community and suggested that the priority given to the resettlement of long-stay patients into supported accommodation is depriving the former group of adequate community care. In support of this, George et al (1991) found high rates of recent psychiatric hospitalisation in a census of single homeless people in Sheffield.

We suggest that in their efforts to counter the "poorly reasoned polemic" of others, Double \& Wong are tilting at windmills: it would be unfortunate if such controversies distracted attention away 